Saudi Journal of Medicine

Abbreviated Key Title: Saudi J Med ISSN 2518-3389 (Print) |ISSN 2518-3397 (Online) Scholars Middle East Publishers, Dubai, United Arab Emirates Journal homepage: https://saudijournals.com/sjm

Original Research Article

\title{
The Effect of Oral Health Knowledge, Attitude and Practice on Periodontal Status among Dental Students
}

Dr. Thanmayi Panguluri, BDS ${ }^{1 *}$, Dr. Aditi Gadhvi, BDS ${ }^{2}$, Dr. Swathi Mannepula, BDS ${ }^{3}$, Dr. Charmiben Patel, BDS ${ }^{2}$, Dr. Divija Takkalapelly, $\mathrm{BDS}^{4}$, Dr. Albi Ngjelo, $\mathrm{BDS}^{5}$

${ }^{1}$ Master's of Public Health, The University of Akron, OHIO, US

${ }^{2}$ K. M. Shah Dental College and Hospital, Gujarat, India

${ }^{3}$ Texas, US

${ }^{4}$ Government Dental College and Hospital, Telangana, India

${ }^{5}$ New York, US

DOI: $10.36348 /$ sjm.2020.v05i03.006

| Received: 19.02.2020 | Accepted: 07.03.2020 | Published: 18.03.2020

*Corresponding author: Dr. Thanmayi Panguluri

\section{Abstract}

Background: A positive behavior as well as attitude of the dental students can be improvised during their undergraduate studies and thereby it is considered as an essential factor as they can further promote the oral self-care habits of their patients and hence the society in general. Objectives: The primary objective of the present study is to relate the oral health knowledge, attitude, as well as practice with the periodontal status of the undergraduate dental students. Materials and Methods: The data were collected through a combination of clinical examination and self-reported questionnaire. The estimated sample size was 234 . The probing depths as well as the clinical attachment loss were measured in the interproximal sites, while the gingival index was calculated on the basis of Ramfjord index teeth. Classification by the CDC and the American Academy of Periodontology was used for periodontal diagnosis. The subjects were divided into three groups. Results: The dental students participated in study were 299. Moreover, significant differences were found among the three groups in their oral health knowledge, attitude, and practice scores. The gingival disease was detected in around $99.3-99.9 \%$ and periodontitis in about $60 \%$ of the dental students irrespective of its severity. Hence a positive correlation has been established between the oral health knowledge and attitude as well as oral hygiene practice. Conclusions: Present study highlighted need in order to improve the oral health knowledge, attitude, and practice of dental students. The gingival as well as the periodontal inflammation was highly prevalent among the participants.

Keywords: Dental students, oral health attitude, knowledge and practice, periodontal status.

Copyright @ 2020: This is an open-access article distributed under the terms of the Creative Commons Attribution license which permits unrestricted use, distribution, and reproduction in any medium for non-commercial use (NonCommercial, or CC-BY-NC) provided the original author and source are credited.

\section{INTRODUCTION}

The oral health is considered as an important component of the general health that has proved to have a direct influence the quality of life. Oral health can also affect the individual's appearance, social functions as well as physical and psychological daily activities [1]. The periodontal health is a major part of the oral health that is based upon the prevention of the inflammatory diseases in the tooth supporting tissue. The oral hygiene practice can be described as any effort that has been performed by the individual in order to remove the supragingival plaque [2]. Several studies have shown that the poor oral hygiene leads to the gingival inflammation and hence establish a linear relationship between the plaque development and presence of gingivitis, which further had been linked to the development of periodontitis [3]. Thereby, it is essential to clean the oral cavity is as it removes the bacterial accumulation and hence prevents the progression of periodontal disease. The dental students play an important role in the promotion of oral health care during their educational years and thereafter [4]. Teaching is of great importance and considered effective if it leads to the profound changes in students' knowledge, attitude, and practice regarding their personal oral health. The oral health knowledge, attitude and oral hygiene practice of the dental students are important because it will affect their ability to translate the information to their patients [5]. Many studies have evaluated the oral health knowledge, attitude, and oral hygiene practice among the health care providers; By investigating their attitude toward the oral health as well as oral hygiene practices demonstrated that the dental students scored higher than the medical students, however, $89 \%$ percent of dental students, and $54 \%$ medical students believed that the regular visits to dentists were important. Some other 
studies concentrated on the changes that occurred during the dental educational progress. When the assessment of the oral health knowledge, attitude, and practice of dental students was done, it was noted that mean scores increased significantly as the dental students progressed in their educational program. However, most of these are questionnaire-based studies, only a few involved the dental examination in their investigation. However, fewer studies have been conducted related to the oral health knowledge, attitude, and practice with periodontal condition. Hence, the primary aim of this study was to relate the oral health knowledge, attitude, and oral hygiene practice with the periodontal condition among both the undergraduate as well as postgraduate dental students.

\section{MATERIALS AND METHODS}

This is a cross-sectional study in which the data was collected randomly from many dental colleges across the world from October 2019 to February 2020. Many dental students had participated in this study by either direct communication or e-mail or indirectly through their supervisors. There was no gender predisposition applied in this study. The exclusion criteria included any medical condition, uncontrolled diseases that affected the periodontal condition, third molars, subjects with complex prosthodontic prosthesis or implants or orthodontic appliances and those who were pregnant. Appointments were arranged accordingly with every participant who agreed to be involved in this study and fulfilled the above-mentioned criteria. The consent forms were signed and confidentiality was maintained. The participant was asked to fill out a questionnaire that was used to assess the oral health knowledge, attitude, and oral hygiene practice. The questionnaire was constructed based on previous articles and American Dental Association recommendations after the validation [6, 7]. The clinical examination was performed by taking measurements of probing depth (PD) and clinical attachment loss (CAL) on the interproximal sites (mesiobuccal and distobuccal), including all the maxillary and mandibular teeth (except third molars) min order to determine the periodontal status by using a intraoral mirror and University of North Carolina (UNC) periodontal probe. Criteria developed by the $\mathrm{CDC}$ and the American Academy of Periodontology (CDC-AAP) were followed to identify subjects with periodontitis. Gingival index (GI) was calculated based upon the Ramfjord index teeth. If their GI score was $<0.1$, the patients were classified as having healthy gingival, mild gingivitis was diagnosed if $\mathrm{GI}=0.1-1$, while moderate gingivitis was identified with GI = $1.1-2$ and the individuals with GI $=2.1-3$ were classified as with severe gingivitis. The study participants were divided into three groups, i.e., Group I (pre-clinical group) consisted of the students in $1^{\text {st }}$ and $2^{\text {nd }}$ year of undergraduate course, those who attend the basic science lectures and laboratory courses. Their oral health knowledge depends mainly upon their background. Group II (clinical group) consisted of dental students in $3^{\text {rd }}$ and $4^{\text {th }}$ year undergraduate course that are involved in different dental specialty courses and start to treat the patients in the clinics. Group III (residents) consisted of interns / house surgeons. The data was entered and analyzed using the SPSS version. The questions were coded, and correct answers had a code of 1 , whereas all the incorrect answers had a code of 0 . On the basis of this, a scale was developed. The knowledge domain score had a range of zero to seven, while the attitude and practice domains had a range of zero to six. The differences in groups were assessed using chi-squared test. The correlation was evaluated by using the Spearman's test. The statistical significance was considered when $p$-value $<0.05$.

\section{RESULTS}

A total of 303 individuals participated in the study. Among them, four participants were excluded due to the either incomplete data that prevented statistical analysis performance or had an uncontrolled diseases that increased the risk for periodontal disease presence. This yielded a final sample size of 299 students, of whom $55.8 \%$ were males and $45.1 \%$ were females. Among the study participants, $30.1 \%$ were in group 1, $44.8 \%$ were in group 2, and $25 \%$ were in group 3. Descriptive data are shown in (Table-1). A comparison was made between the three groups in oral health knowledge, attitude, and oral hygiene practice. As the students progressed in their education, their scores increased significantly $(p$-value $=0.000,0.017$, 0.000 , respectively) (Table-2). The clinical examination indicated that group 2 had the highest mean of gingival inflammation severity $($ mean $=1.16)$. On the contrary, group 3 showed the healthiest gingiva $($ mean $=0.96$ ) The difference between the three groups was statistically significant $(p$-value $=0.001)$ (Table-3). Among the participating dental students, group 2 presented with more mild, moderate, and severe periodontitis than group 1 and group 3 (30.1, 44.8, and 25\%, respectively) (Table-4). On correlating all the studied variables, a significant positive correlation was found between the severity of gingivitis and periodontal diagnosis. A significant positive correlation was detected between the oral health knowledge, attitude, and oral hygiene practices. Whereas, the correlation between oral health knowledge, attitude, and oral hygiene practice with periodontal status did not reach a significant level ( $p=$ $0.79,0.61,0.61$, respectively). 
Table-1: Characteristics of study participants $(n=299)$

\begin{tabular}{|l|l|l|l|}
\hline Characteristics & \multicolumn{2}{|l|}{$\boldsymbol{n}$} & $\mathbf{\%}$ \\
\hline Gender & Male & 164 & $54.8 \%$ \\
\cline { 2 - 4 } & Female & 135 & $45.1 \%$ \\
\cline { 2 - 4 } & Total & 299 & $100.0 \%$ \\
\hline Dental education & Group 1 & 90 & $30.1 \%$ \\
\cline { 2 - 4 } & Group 2 & 134 & $44.8 \%$ \\
\cline { 2 - 4 } & Group 3 & 75 & $25.0 \%$ \\
\cline { 2 - 4 } & Total & 299 & $100.0 \%$ \\
\hline Smoking status & Regular smoker & 46 & $15.3 \%$ \\
\cline { 2 - 4 } & Former smoker & 11 & $3.6 \%$ \\
\cline { 2 - 4 } & Never smoker & 219 & $73.2 \%$ \\
\cline { 2 - 4 } & Occasional smoker & 23 & $7.6 \%$ \\
\cline { 2 - 4 } & Total & 299 & $100.0 \%$ \\
\hline
\end{tabular}

Table-2: Comparison among Group 1, Group 2 and Group 3 on the basis of knowledge, attitude and practice ranks

\begin{tabular}{|c|l|l|l|l|l|l|l|}
\hline \multicolumn{2}{|c|}{ Variables } & $\boldsymbol{n}$ & Mean & SD & Mean rank & Chi-square & $\boldsymbol{p}$-Value \\
\hline Knowledge & Group 1 & 90 & 2.97 & 1.27 & 99.66 & 43.628 & $\mathbf{0 . 0 0 0}$ \\
\hline & Group 2 & 134 & 3.98 & 1.09 & 160.98 & & \\
\hline & Group 3 & 75 & 4.21 & 1.22 & 177.82 & & \\
\hline Attitude & Group 1 & 90 & 4.22 & 1.18 & 132.47 & 8.146 & $\mathbf{0 . 0 1 7}$ \\
\hline & Group 2 & 134 & 4.44 & 1.03 & 147.73 & & \\
\hline Practice & Group 3 & 75 & 4.72 & 1.09 & 169.16 & & \\
\hline & Group 1 & 90 & 2.54 & 1.17 & 102.25 & 39.506 & $\mathbf{0 . 0 0 0}$ \\
\hline & Group 2 & 134 & 3.60 & 1.17 & 170.74 & & \\
\hline & Group 3 & $\mathbf{7 5}$ & $\mathbf{3 . 5 3}$ & $\mathbf{1 . 2 8}$ & $\mathbf{1 6 4 . 1 5}$ & & \\
\hline
\end{tabular}

Table-3: Comparison of the gingival index score among Group 1, Group 2 and Group 3

\begin{tabular}{|l|l|l|l|l|l|l|c|}
\hline Gingival index & $\boldsymbol{n}$ & Mean & SD & Mean ranks & Chi-square & df & $\boldsymbol{p}$-Value \\
\hline Group 1 & 90 & 1.13 & 0.38 & 152.11 & 13.89 & 2 & $\mathbf{0 . 0 0 1}$ \\
\cline { 1 - 5 } Group 2 & 134 & 1.16 & 0.40 & 163.34 & & & \\
\hline Group 3 & 75 & 0.96 & 0.41 & 117.49 & & & \\
\hline Total & $\mathbf{2 9 9}$ & $\mathbf{1 . 1 0}$ & $\mathbf{0 . 4 0}$ & & & & \\
\hline
\end{tabular}

Table 4: Comparison of the periodontal diagnosis among Group 1, Group 2 and Group 3

\begin{tabular}{|c|c|l|l|l|l|l|}
\hline Students & \multicolumn{4}{|l|}{ Periodontal diagnosis } & Total \\
\hline & & Mild & Moderate & Severe & No periodontitis & \\
\hline Group 1 & $n$ & 28 & 25 & 2 & 35 & $\mathbf{9 0}$ \\
\cline { 2 - 7 } & $(\%)$ & $30.4 \%$ & $30.1 \%$ & $22.2 \%$ & $29.9 \%$ & $\mathbf{3 0 . 1 \%}$ \\
\hline Group 2 & $n$ & 37 & 42 & 4 & 51 & $\mathbf{1 3 4}$ \\
\cline { 2 - 7 } & $(\%)$ & $40.2 \%$ & $50.6 \%$ & $44.4 \%$ & $43.5 \%$ & $\mathbf{4 4 . 8 \%}$ \\
\hline Group 3 & $n$ & 25 & 16 & 3 & 31 & $\mathbf{7 5}$ \\
\cline { 2 - 7 } & $(\%)$ & $27.1 \%$ & $19.2 \%$ & $33.3 \%$ & $26.4 \%$ & $\mathbf{2 5 . 0 \%}$ \\
\hline Total & $n$ & 90 & 83 & 9 & 117 & $\mathbf{2 9 9}$ \\
\hline & $(\%)$ & $\mathbf{1 0 0 \%}$ & $\mathbf{1 0 0 . 0 \%}$ & $\mathbf{1 0 0 . 0 \%}$ & $\mathbf{1 0 0 . 0 \%}$ & $\mathbf{1 0 0 . 0 \%}$ \\
\hline
\end{tabular}

\section{DISCUSSION}

Worldwide, periodontal disease is one of the most common oral diseases that causes global burden. It has high prevalence and considered to be a major public health problem in many countries [6]. Although the dental plaque is considered as a primary etiologic factor in development of the periodontal diseases, but the alteration of inflammatory response may enhance the periodontal tissue destruction. This can occur due to uncontrolled diabetes, psychosocial stress, smoking as well as fluctuation in hormonal levels [7]. The dental students are considered as future oral health providers. In order to motivate their patients to practice good oral hygiene and implement a better oral health, they should be self-motivated. The improvement was statistically significant among preclinical, clinical-year undergraduate students and interns in oral health knowledge as well as attitude scores. Similar studies had illustrated that as the students progressed through their dental educational program, their oral health knowledge, attitude, and oral hygiene practice have improved [8]. The dental students have been proven to suffer from high levels of stress in comparison to other specialties. The stress level increases as they progress in their educational program $[9,10]$. In an attempt to investigate relationship between different variables, we found that as the oral health knowledge increased, the students developed a positive attitude and performed a better oral hygiene. Moreover, this correlation was 
statistically significant. Additionally, a statistically significant positive correlation has been established between the gingival inflammation severity and periodontal disease severity. Thereby, this agrees with the previously proven evidence that the gingivitis is a risk factor for developing periodontitis.

\section{Limitations \& Strengths}

On the basis of CDC-AAP classification, CAL may be considered more accurate than the PD, depending upon CAL alone could include the healthy reduced periodontium or CAL due to other causes than the periodontal disease in the periodontitis category. Similarly, depending upon PD alone results in the underestimation of prevalence of periodontitis, especially in the older individuals. Thereby, a combination of both PD and CAL will result in more accurate diagnoses $[11,12]$. The periodontal examination was performed by a single examiner, which increased the reliability of measurements taken and thereby reduced the variations and errors. On the contrary, the CDC-AAP classification was based mainly on the interproximal site measurements, by virtue of assumption that these sites were most affected. Thereby this may lead to underestimation of periodontal disease. Neither furcation involvement nor BOP was recorded, even though such measurements may provide the additional information that could help diagnose the periodontal disease accurately. Moreover, including female dental students may be considered a weak point because the hormonal fluctuation was not considered. Although a positive correlation was established between the gingivitis severity and periodontal inflammation severity. As being health care providers dentists are a role model for their patients, families and friends and required to teach them the necessary skills in order to attain imperative oral health [11]. The policy makers and educators need to assess the educational programs in order to further bridge the gaps for the betterment oral health care. Thereby, it is suggested that the oral health and preventive dentistry courses should be stressed in the curriculum programs. Moreover, such topics should start early in the dental training. With the intensive oral health promotion campaigns, the periodontal disease burden can be reduced. Furthermore, establishing an oral health clinic for annual examination and providing the required treatment for the dental students are considered a valuable step in improving the oral health. One step towards emphasizing the role of such a clinic is to consider the annual examination as one of the requirements needed in order to progress in a dental training program [12].

\section{CONCLUSIONS}

In light of the present results, although a significant improvement was detected in the oral health knowledge, attitude as well as the oral hygiene practice as the dental students progressed from undergraduate preclinical years to clinical years; the scores were considerably lower than what was expected. High prevalence of the gingival inflammation was detected among the dental students. Moreover, more than half of participants presented with the periodontal disease, regardless of severity. Thereby, it can be stated that improving the oral health knowledge leads to the better attitude and preferable oral hygiene practice.

\section{REFERENCES}

1. FDI World Denal Federation. (2016). FDI's definition of oral health www.fdiworlddental.org/oral-health/fdidefinition-of-oral-health Updated.

2. Gomes, A. S., Abegg, C., \& Fachel, J. M. G. (2009). Relationship between oral clinical conditions and daily performances. Brazilian oral research, 23(1), 76-81.

3. Lang, N. P., \& Bartold, P. M. (2018). Periodontal health. Journal of periodontology, 89, S9-S16.

4. Lindhe, J., \& Lang, N. (2017). Clinical Periodontology and Implant Dentistry. 6th ed. UK: Wiley Blackwell.

5. Löe, H., Theilade, E., \& Jensen, S. B. (1965). Experimental gingivitis in man. The Journal of periodontology, 36(3), 177-187.

6. Page RC, Schroeder HE. Pathogenesis of inflammatory periodontal disease. A summary of current work. Lab Invest 1976;34(3):235-249

7. Hosing, A., Hiremath, A. M., Vadavadagi, V., Bansal, A., \& Kahar, A. (2016). Oral Hygiene Practices in Dental Students. Journal of Oral Health \& Community Dentistry, 10(1):30-34.

8. Kumar, S., Motwani, K., Dak, N., Balasubramanyam, G., Duraiswamy, P., \& Kulkarni, S. (2010). Dental health behaviour in relation to caries status among medical and dental undergraduate students of Udaipur district, India. International journal of dental hygiene, 8(2), 86-94.

9. Al-Ansari, J., Honkala, E., \& Honkala, S. (2003). Oral health knowledge and behavior among male health sciences college students in Kuwait. BMC oral health, 3(1), 2.

10. Ali, D. A. (2016). Assessment of oral health attitudes and behavior among students of Kuwait University Health Sciences Center. Journal of International Society of Preventive \& Community Dentistry, 6(5), 436-446.

11. Beck, J. D., Koch, G. G., \& Offenbacher, S. (1994). Attachment loss trends over 3 years in community- dwelling older adults. Journal of periodontology, 65(8), 737-743.

12. Page, R. C., \& Eke, P. I. (2007). Case definitions for use in population- based surveillance of periodontitis. Journal of periodontology, 78, 1387 1399. 